\title{
The Aperture
}

\section{Auer Rods Galore!}

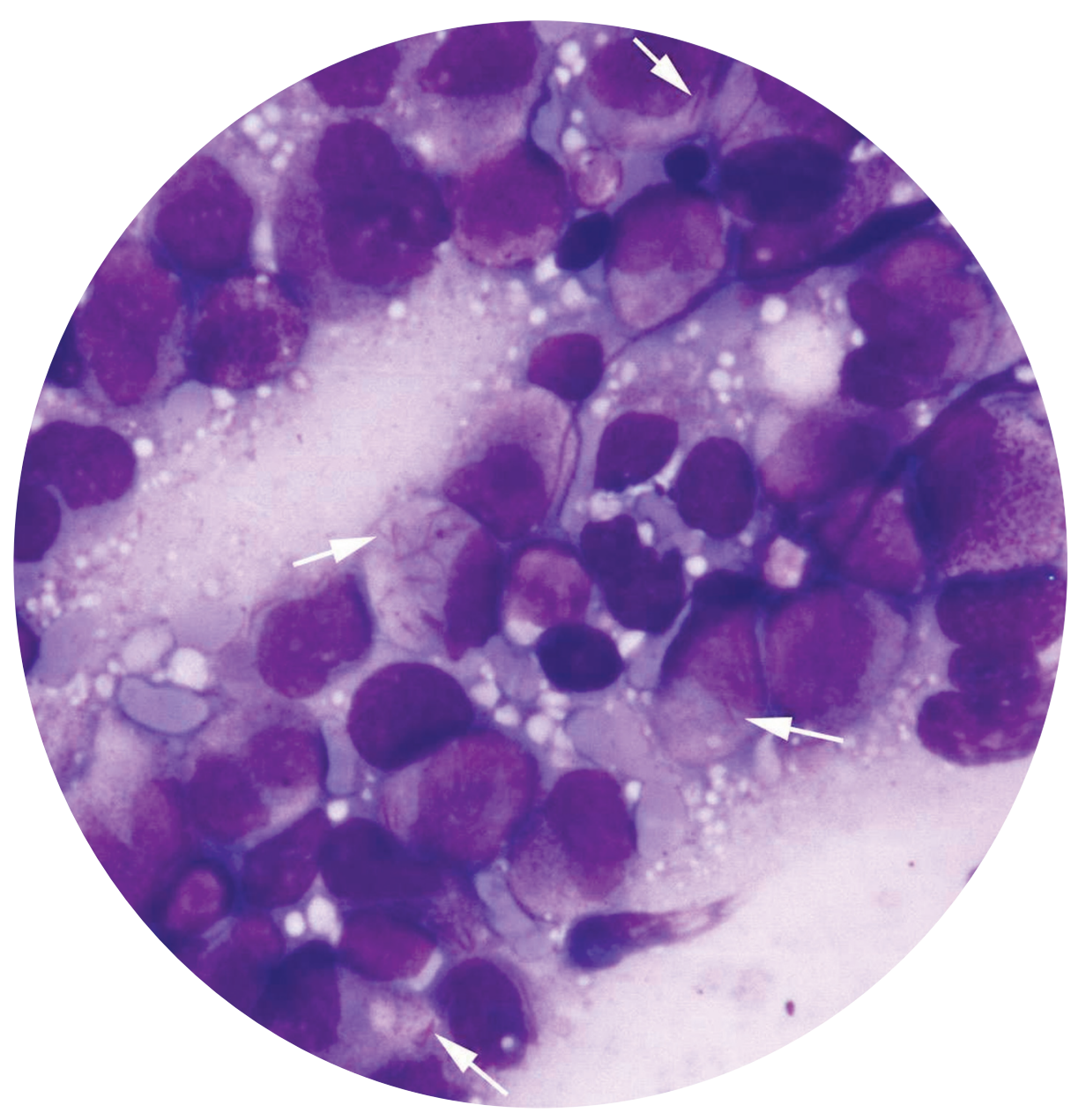

The diagnostic intracellular inclusions (Auer rods) found in this touch preparation of a core bone marrow biopsy helped provide basis for the diagnosis in this case.

The patient, a 48-year-old man, presented with increasing fatigue and pancytopenia. A bone marrow biopsy demonstrated a marked increase in hypergranular, immature myeloid cells, as well as a plethora of Auer rods. The diagnosis was confirmed by cytogenetic studies which showed a C15:17 translocation [t(15:17)].

\section{Keywords:}

Bone marrow cells;

Bone marrow examination;

Pancytopenia;

Asthenia

\section{Diagnosis - Acute Promyelocytic Leukemia}

Contributed by Joseph J. Mazza, MD, Department of Hematology/Oncology, Marshfield Clinic, 1000 N. Oak Avenue, Marshfield, Wisconsin 54449. Telephone: 715-387-5426; Fax: 715-389-3808; Email: mazza.joseph@ marshfieldclinic.org

The Aperture, like the opening in the lens of a microscope that allows light to pass through, is a forum for art, humor, and images that provides a portal for new or different views of medicine and research. 